\title{
IMPERFECTIONS IN CALCULATIONS OF GUYED LATTICE MASTS
}

\author{
M. MATUSZKIEWICZ ${ }^{1}$
}

\begin{abstract}
Influence of geometric imperfections of mast shaft in form of initial mast span curvatures both on internal forces status in the structure elements as well as on those elements effort, which is particularly important at the design stage, was analysed based on an example of certain specific mast. The calculations were performed taking into account $L / 1000$ imperfections equal to the permissible assembly deviations as per [1], and $L / 500$ equal to initial imperfections as for uniform built-up columns according to [2]. Remarks and final conclusions have practical meaning and can be useful in design practice.
\end{abstract}

Keywords: guyed mast, static analysis, initial geometric imperfections

\section{INTRODUCTION}

From the point of view of correctness of mast structure calculations as per the second order theory, i.e. taking into account influence of deflections on equilibrium conditions, a structure featuring initial geometrical imperfections should be analysed. Unfortunately, in Eurocode [1] there are no guidelines pertaining to the form of adoption of the initial mast shaft imperfections and their size. There is also no information that such imperfections can be omitted from calculations (such provision exists, e.g. in the German mast standard [3]). Reference to provisions [2], pertaining to calculations of uniform built-up columns in typical steel structures is, for many reasons, arguable. Guyed masts belong to specific structures in which, due to geometrical non-linearity of the guys, rigidity of elastic supports in the guy fixing point feature high variability and depend on current mast configuration. Those supports differ, therefore, considerably from typical steel structure supports so, the mast shaft buckling form is different than that of columns in typical structures. This issue requires consideration and will be a subject of further analyses. An assumption was made in this paper that the shaft imperfection shape has a form of span buckling between the guy levels and to such form recommendations from [1], regarding tolerances in execution, pertain.

1 Koszalin University of Technology, Koszalin, Poland, e-mail: m.mat@wilsig.tu.koszalin.pl 
The principal objective of this study was an attempt to reply the question what impact on the mast structure elements effort have the analysed types of initial mast shaft imperfections.

\section{MAIN ASSUMPTIONS AND MAST STRUCTURE DESCRIPTION}

The calculations pertain to the guyed lattice mast structure featuring the height of 200 $\mathrm{m}$ (Figure 1.). The mast shaft was designed as S355 steel in form of three-walled lattice with side width $a=2.0 \mathrm{~m}$. As leg members $\varnothing 168.3 / 12.5 \mathrm{~mm}$ pipes were used, and as mast face lacing - pipes $\varnothing 76.1 / 4.0 \mathrm{~mm}$. The mast guys have been fixed at the following height values: $65.0 \mathrm{~m}, 125.0 \mathrm{~m}$ and $175.0 \mathrm{~m}$. For guys spiral strand steel ropes 1x61, $\varnothing 32 \mathrm{~mm}$, featuring strength $R_{r}=1570 \mathrm{MPa}$ and the minimum breaking force of 823.0 $\mathrm{kN}$ were used. The assumed values of guy initial tension forces at all guy levels are the same and amount to $75 \mathrm{kN}$ (in accordance with the recommendations given in [1] - they do not exceed $10 \%$ of the rope breaking force). An assumption was made that the mast would be located in the second zone of wind load as per [4], in the II $^{\text {nd }}$ category area. The mean wind load as well as patch loads on the mast structure diagrams, as per [1], are shown in Figure 2. The structure has been qualified to the second reliability class, therefore, the partial factors for loads are equal to: 1.1 - for permanent loads and 1.4 - for variable loads. Structure's own weight (excluding its outfit) and mast shaft and guys wind loading for two most unfavourable directions of wind action W1 and W2 (Figure 2.) were taken into account in the calculations.

The calculations were performed for the "perfect" type structure, i.e. with an assumption that the initial mast shaft geometrical imperfections did not exist and for the "imperfect" type structure assuming initial buckling of mast spans between the guy levels featuring the maximum amplitude values as equal to:

- $\quad v_{0}=L / 1000-$ values of permissible shaft assembly deviations as per [1],

- $\quad v_{0}=L / 500$ - values of initial imperfections as for uniform built-up columns as per [2].

An assumption was made in the mast analysis that the initial mast span curvature has been described by a parabolic function, therefore, the value of the substitute transversal load for bar curvature is constant and amounts to $q=8 N v_{0} / L^{2}$ [5], where $N$-axial force in mast span, $v_{0}$ - amplitude of buckling equal to the assumed initial imperfections and $L$ - mast span length. Diagrams of the substitute mast shaft loads from the initial imperfections are demonstrated in Figure 3. 


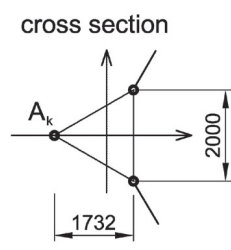

lacing on mast face
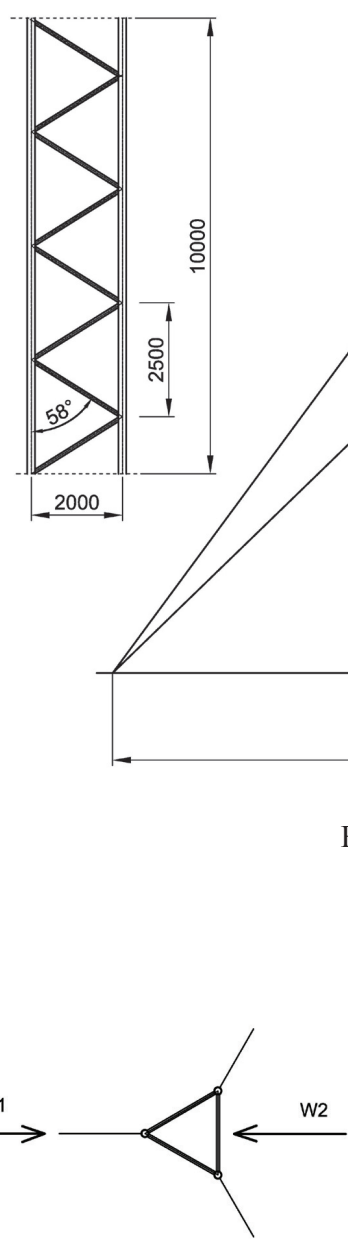

Fig. 1. Mast structure diagram

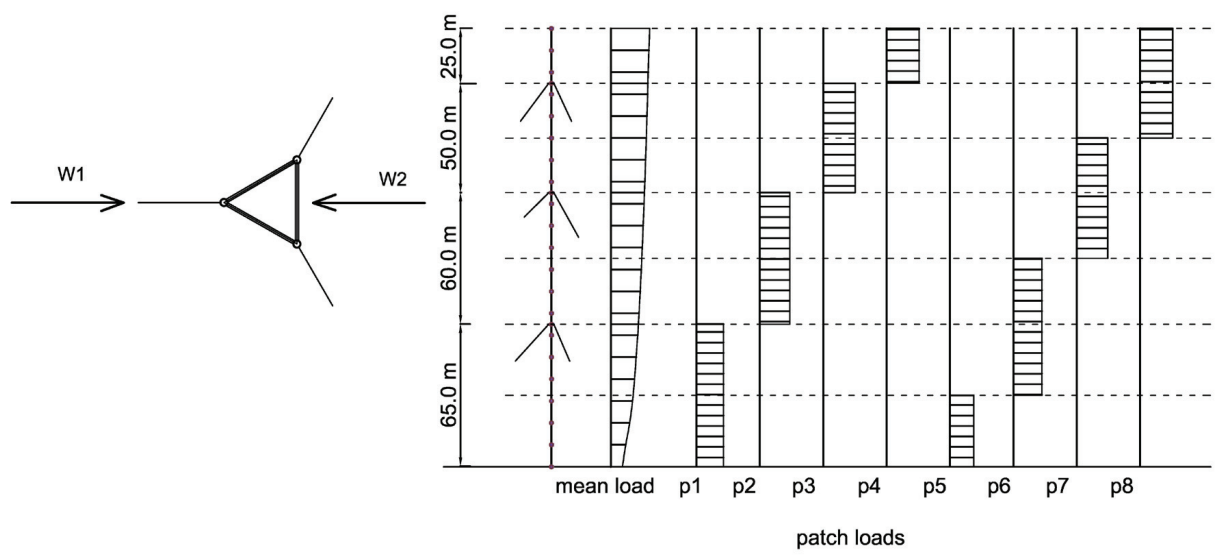

Fig. 2. Directions and wind load diagrams for the mast structure 
a)

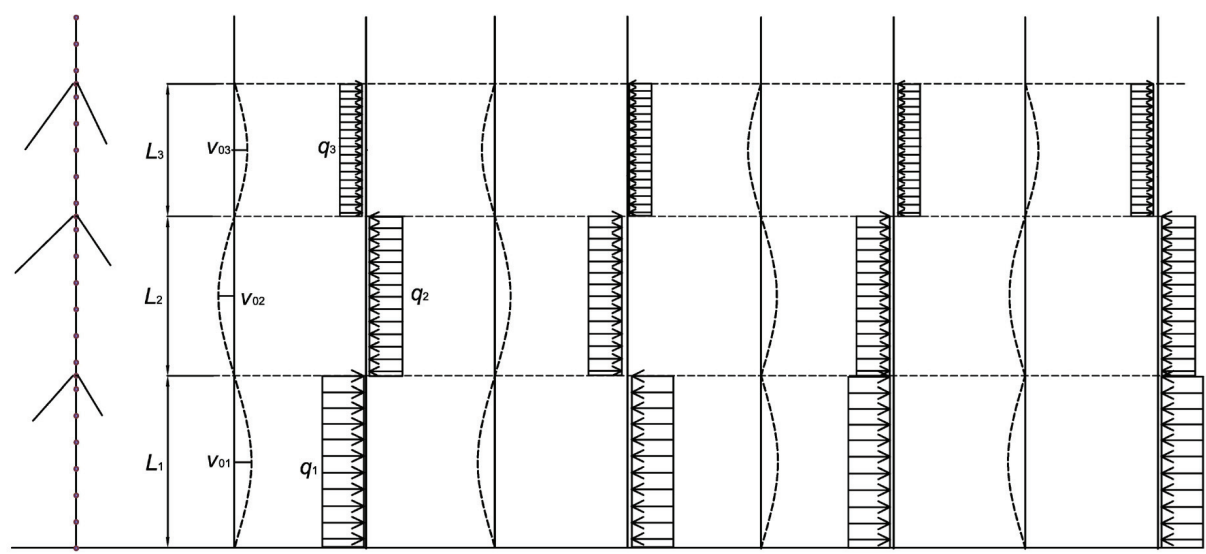

Fig. 3. Geometrical mast shaft imperfections and the corresponding equivalent loads

\section{Static calculations}

The static calculations were performed using the Mast programme described in [6]. The global elastic analysis as per the second order theory was applied taking into account, in calculations, nonlinear guy properties. An assumption was made in the static analysis that a lattice be substituted by a solid bar featuring proper geometrical and strength characteristics taking into account compression, bending, shear and torsional flexibility. The mast structure diagram with applied bar numbering is show in Figure 4.

Value of the equivalent load from imperfections acting on the mast span depends on the value of the axial force in the bar. As the real dynamic wind action on the mast structure was replaced, as per [1], with quasi equivalent static load composed of the mean wind load acting on the entire height structure and a number of patch loads, acting only on structure fragments, taking mast imperfections into account in calculations became very laborious and complicated.

At the first stage, calculations for the "perfect" type structure should be performed for particular combinations of the mean load and subsequent wind patch loads. For each of those combinations separately, values of the substitute load are determined based on the calculated values of the normal force in particular mast spans, and then calculations are performed again for particular load combinations taking additionally into account the substitute loads in accordance with the assumed direction of the mast shaft span buckling. 
Static calculations taking into account the mast shaft imperfections in the form of the equivalent loads were verified by calculations with direct assumption of the curved mast shaft. The convergence of the results was good.

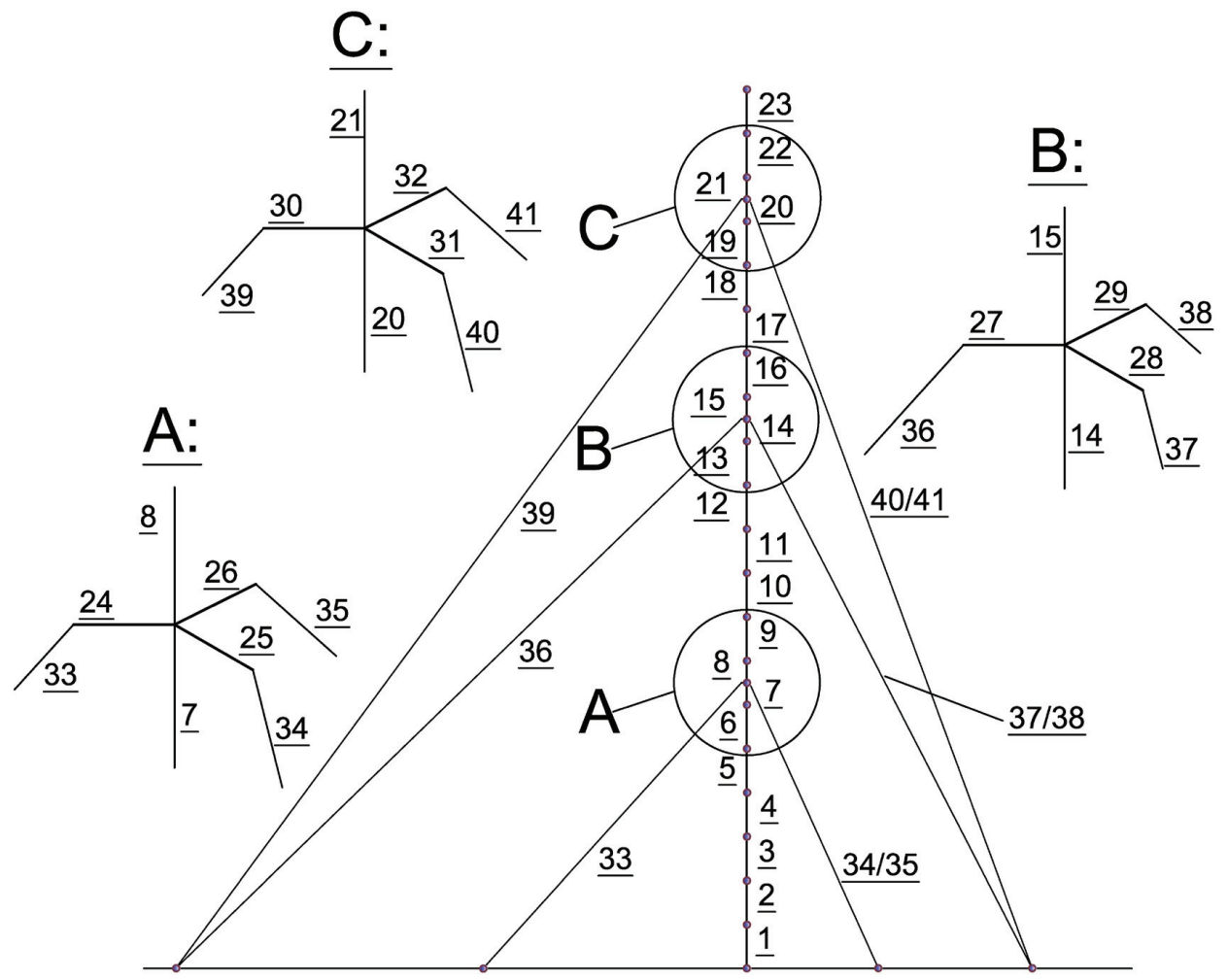

Fig. 4. Numbering of the bars

An example of the method of calculation of substitutes loads from initial imperfections is shown in Table 1.

Based on the obtained calculation results pertaining to particular combinations, in accordance with the procedure described in [1], total effects of loading in each mast structure component is determined adding (or subtracting) to the mean wind load effects, the total effect of patch loads [see 7]. In the case of the analysed mast structure, taking into account two most unfavourable directions of wind load, four different patterns of the initial imperfections equivalent load action and two different values of mast span curvature maximum amplitudes, calculations for 162 various load combinations had to be done. 
Table 1

An exemplary method of calculating the substitute load of imperfection of mast shaft - wind direction W1, imperfections $v_{0}=L / 500$

\begin{tabular}{|c|c|c|c|c|c|c|c|}
\hline \multirow{2}{*}{ Load combination } & \multirow{2}{*}{ Span No } & \multicolumn{2}{|c|}{$\begin{array}{l}\text { Shaft normal force } \\
{[\mathrm{kN}]}\end{array}$} & \multirow{2}{*}{$\begin{array}{c}\text { Mean force } \\
\text { value } N_{s r} \\
{[\mathrm{kN}]}\end{array}$} & \multirow{2}{*}{$\begin{array}{c}\text { Span } \\
\text { length } L \\
{[\mathrm{~m}]}\end{array}$} & \multirow{2}{*}{$\begin{array}{c}\text { Imperfection } \\
\text { value } \\
v_{0}=L / 500 \\
{[\mathrm{~m}]}\end{array}$} & \multirow{2}{*}{$\begin{array}{c}\text { Substitute } \\
\text { load } \\
q=8 N v_{0} / L^{2} \\
{[\mathrm{kN} / \mathrm{m}]}\end{array}$} \\
\hline & & $N_{i}$ & $N_{k}$ & & & & \\
\hline \multirow{3}{*}{$G+F_{m, W}$} & 1 & 1084.1 & 944.8 & 1014.5 & 65 & 0.13 & 0.250 \\
\hline & 2 & 754.5 & 621.2 & 687.9 & 60 & 0.12 & 0.183 \\
\hline & 3 & 417.6 & 308.6 & 363.1 & 50 & 0.10 & 0.116 \\
\hline \multirow{3}{*}{$G+F_{m, W}+F_{P W 1}$} & 1 & 1144 & 1004.7 & 1074.3 & 65 & 0.13 & 0.265 \\
\hline & 2 & 789.5 & 656.2 & 722.9 & 60 & 0.12 & 0.193 \\
\hline & 3 & 437.8 & 328.7 & 383.3 & 50 & 0.10 & 0.123 \\
\hline \multirow{3}{*}{$G+F_{m, W}+F_{P W 2}$} & 1 & 1134.4 & 995.1 & 1064.7 & 65 & 0.13 & 0.262 \\
\hline & 2 & 799.5 & 666.2 & 732.9 & 60 & 0.12 & 0.195 \\
\hline & 3 & 438.2 & 329.1 & 383.7 & 50 & 0.10 & 0.123 \\
\hline \multirow{3}{*}{$G+F_{m, W}+F_{P W 3}$} & 1 & 1121.3 & 981.9 & 1051.6 & 65 & 0.13 & 0.259 \\
\hline & 2 & 792.7 & 659.5 & 726.1 & 60 & 0.12 & 0.194 \\
\hline & 3 & 447.8 & 338.8 & 393.3 & 50 & 0.10 & 0.126 \\
\hline \multirow{3}{*}{$G+F_{m, W}+F_{P W 4}$} & 1 & 1097.8 & 958.5 & 1028.1 & 65 & 0.13 & 0.253 \\
\hline & 2 & 769.1 & 635.9 & 702.5 & 60 & 0.12 & 0.187 \\
\hline & 3 & 432.7 & 323.7 & 378.2 & 50 & 0.10 & 0.121 \\
\hline \multirow{3}{*}{$G+F_{m, W}+F_{P W 5}$} & 1 & 1105.5 & 966.2 & 1035.9 & 65 & 0.13 & 0.255 \\
\hline & 2 & 769.1 & 635.8 & 702.5 & 60 & 0.12 & 0.187 \\
\hline & 3 & 425.9 & 316.8 & 371.3 & 50 & 0.10 & 0.119 \\
\hline \multirow{3}{*}{$G+F_{m, W}+F_{P W 6}$} & 1 & 1139.5 & 1000.2 & 1069.9 & 65 & 0.13 & 0.263 \\
\hline & 2 & 792 & 658.7 & 725.3 & 60 & 0.12 & 0.193 \\
\hline & 3 & 437.4 & 328.4 & 382.9 & 50 & 0.10 & 0.123 \\
\hline \multirow{3}{*}{$G+F_{m, W}+F_{P W 7}$} & 1 & 1129.3 & 990 & 1059.7 & 65 & 0.13 & 0.261 \\
\hline & 2 & 798.8 & 665.5 & 732.1 & 60 & 0.12 & 0.195 \\
\hline & 3 & 442.3 & 333.3 & 387.8 & 50 & 0.10 & 0.124 \\
\hline \multirow{3}{*}{$G+F_{m, W}+F_{P W 8}$} & 1 & 1120.7 & 981.3 & 1051 & 65 & 0.13 & 0.259 \\
\hline & 2 & 792.8 & 659.5 & 726.1 & 60 & 0.12 & 0.194 \\
\hline & 3 & 453.9 & 344.9 & 399.4 & 50 & 0.10 & 0.128 \\
\hline
\end{tabular}




\section{Calculation results}

Values of internal forces in mast structure elements obtained from the static analysis are presented in the below tables separately for the "perfect" type structure (Table 2 and 3) and for the structure with initial mast shaft curvatures (Table 4 and 5).

Table 2

Values of internal forces in the mast shaft spans - calculations without imperfections

\begin{tabular}{|c|c|c|c|c|c|c|c|c|c|c|}
\hline \multicolumn{2}{|c|}{ Mast shaft span } & \multicolumn{3}{c|}{1} & \multicolumn{3}{c|}{2} & \multicolumn{3}{c|}{3} \\
\hline \multicolumn{2}{|c|}{ Bar No } & 1 & 4 & 7 & 8 & 11 & 14 & 15 & 17 & 20 \\
\hline \multirow{3}{*}{ Wind W1 } & $N[\mathrm{kN}]$ & -1204.9 & -1132.3 & -1065.6 & -854.3 & -787.9 & -721.1 & -483.6 & -441.2 & -374.6 \\
\cline { 2 - 11 } & $M[\mathrm{kNm}]$ & 0 & 607.06 & -351.56 & -604.21 & 330.37 & -463.82 & -619.57 & -435.98 & -506.49 \\
\hline \multirow{2}{*}{ Wind W2 } & $N[\mathrm{kN}]$ & -1121.5 & -1048.7 & -982.1 & -787.2 & -720.6 & -653.9 & -455.9 & -413.5 & -346.7 \\
\cline { 2 - 11 } & $M[\mathrm{kNm}]$ & 0 & -630.73 & 320.11 & 514.69 & -472.32 & 634.36 & 788.62 & 634.61 & 528.42 \\
\hline
\end{tabular}

Table 3

Forces in mast guys - calculations without imperfections

\begin{tabular}{|c|c|c|c|c|c|c|c|c|c|c|}
\hline \multicolumn{2}{|c|}{ Guy level } & \multicolumn{3}{|c|}{ I } & \multicolumn{3}{c|}{ II } & \multicolumn{3}{c|}{ III } \\
\hline \multicolumn{2}{|c|}{ Guy number } & 33 & 34 & 35 & 36 & 37 & 38 & 39 & 40 & 41 \\
\hline Wind W1 & $S[\mathrm{kN}]$ & 189.0 & 71.0 & 71.0 & 187.5 & 77.8 & 77.8 & 236.8 & 83.0 & 83.0 \\
\hline Wind W2 & $S[\mathrm{kN}]$ & 73.1 & 139.1 & 139.1 & 64.9 & 130.1 & 130.1 & 49.1 & 166.5 & 166.5 \\
\hline
\end{tabular}

It can be noted from the results obtained that taking the initial imperfections into account in static analysis with relation to the "perfect" type structure calculations has the most significant impact on the change of span moment values in the mast shaft (similar conclusions have been presented in [8]). In the calculations with $L / 1000$ imperfections, values of the span moments in spans 1 and 2 increased by $15 \%$ whereas in the case of $L / 500$ imperfections - by approx. 30\%. For span 3 those differences amounted to max. $3 \%$. In the case of supporting moments significant differences (12\% for $L / 1000$ imperfections and $16 \%$ for $L / 500$ imperfections) were observed for the second guy levels. Taking into account of the initial imperfections in calculations has, nevertheless, no practical impact on values of the normal forces in the mast shaft - the differences did not exceed $1 \%$. In the case of the maximum values of forces in guys at their particular levels of fixing, significant differences were noted for the lowest guys. Taking into account $L / 1000$ imperfection, $15 \%$ increase, and for $L / 500,27 \%$ increase, was noted. The maximum difference at the highest guy level, where the highest force in the guy was noted, did not exceed $3 \%$. 
Table 4

The most unfavourable values of internal forces in the mast shaft spans - calculations taking into account the initial imperfections

\begin{tabular}{|c|c|c|c|c|c|c|c|}
\hline \multirow{2}{*}{$\begin{array}{l}\text { Span } \\
\text { No }\end{array}$} & \multirow{2}{*}{$\begin{array}{l}\text { Bar } \\
\text { No }\end{array}$} & \multicolumn{3}{|c|}{ Imperfections $v=L / 1000$} & \multicolumn{3}{|c|}{ Imperfections $v=L / 500$} \\
\hline & & \multicolumn{2}{|c|}{ Force values } & Calculation & \multicolumn{2}{|c|}{ Force values } & Calculation \\
\hline \multirow{6}{*}{1} & \multirow{2}{*}{1} & $N[\mathrm{kN}]$ & -1209.0 & \multirow{2}{*}{$\begin{array}{c}\text { wind W1 } \\
\text { imp. as per Fig. 3c) }\end{array}$} & $N[\mathrm{kN}]$ & -1213.5 & \multirow{2}{*}{$\begin{array}{c}\text { wind W1 } \\
\text { imp. as per Fig. 3c) }\end{array}$} \\
\hline & & $M[\mathrm{kNm}]$ & 0 & & $M[\mathrm{kNm}]$ & 0 & \\
\hline & \multirow{2}{*}{4} & $N[\mathrm{kN}]$ & -1133.5 & \multirow{2}{*}{$\begin{array}{c}\text { wind W1 } \\
\text { imp. as per Fig. 3a) }\end{array}$} & $N[\mathrm{kN}]$ & -1135.5 & \multirow{2}{*}{$\begin{array}{c}\text { wind W1 } \\
\text { imp. as per Fig. 3a) }\end{array}$} \\
\hline & & $M[\mathrm{kNm}]$ & 697.02 & & $M[\mathrm{kNm}]$ & 773.58 & \\
\hline & \multirow{2}{*}{7} & $N[\mathrm{kN}]$ & -1064.3 & \multirow{2}{*}{$\begin{array}{c}\text { wind W1 } \\
\text { imp. as per Fig. } 3 b \text { ) }\end{array}$} & $N[\mathrm{kN}]$ & -1062.7 & \multirow{2}{*}{$\begin{array}{c}\text { wind W1 } \\
\text { imp. as per Fig. 3b) }\end{array}$} \\
\hline & & $M[\mathrm{kNm}]$ & -371.70 & & $M[\mathrm{kNm}]$ & -395.24 & \\
\hline \multirow{6}{*}{2} & \multirow{2}{*}{8} & $N[\mathrm{kN}]$ & -853.4 & \multirow{2}{*}{$\begin{array}{c}\text { wind W1 } \\
\text { imp. as per Fig. 3c) }\end{array}$} & $N[\mathrm{kN}]$ & -852.7 & \multirow{2}{*}{$\begin{array}{c}\text { wind W1 } \\
\text { imp. as per Fig. 3c) }\end{array}$} \\
\hline & & $M[\mathrm{kNm}]$ & -646.56 & & $M[\mathrm{kNm}]$ & -692.8 & \\
\hline & \multirow{2}{*}{11} & $N[\mathrm{kN}]$ & -787.6 & \multirow{2}{*}{$\begin{array}{c}\text { wind W1 } \\
\text { imp. as per Fig. 3b) }\end{array}$} & $N[\mathrm{kN}]$ & -787.1 & \multirow{2}{*}{$\begin{array}{c}\text { wind W1 } \\
\text { imp. as per Fig. 3b) }\end{array}$} \\
\hline & & $M[\mathrm{kNm}]$ & 381.70 & & $M[\mathrm{kNm}]$ & 434.13 & \\
\hline & \multirow{2}{*}{14} & $N[\mathrm{kN}]$ & -656.9 & \multirow{2}{*}{$\begin{array}{c}\text { wind W1 } \\
\text { imp. as per Fig. 3b) }\end{array}$} & $N[\mathrm{kN}]$ & -658.9 & \multirow{2}{*}{$\begin{array}{c}\text { wind W1 } \\
\text { imp. as per Fig. 3b) }\end{array}$} \\
\hline & & $M[\mathrm{kNm}]$ & 686.62 & & $M[\mathrm{kNm}]$ & 730.46 & \\
\hline \multirow{6}{*}{3} & \multirow{2}{*}{15} & $N[\mathrm{kN}]$ & -460.5 & \multirow{2}{*}{$\begin{array}{c}\text { wind W2 } \\
\text { imp. as per Fig. 3b) }\end{array}$} & $N[\mathrm{kN}]$ & -464.0 & \multirow{2}{*}{$\begin{array}{c}\text { wind W2 } \\
\text { imp. as per Fig. 3b) }\end{array}$} \\
\hline & & $M[\mathrm{kNm}]$ & 828.44 & & $M[\mathrm{kNm}]$ & 858.42 & \\
\hline & \multirow{2}{*}{17} & $N[\mathrm{kN}]$ & -418.1 & \multirow{2}{*}{$\begin{array}{c}\text { wind W2 } \\
\text { imp. as per Fig. 3b) }\end{array}$} & $N[\mathrm{kN}]$ & -421.6 & \multirow{2}{*}{$\begin{array}{c}\text { wind W2 } \\
\text { imp. as per Fig. 3b) }\end{array}$} \\
\hline & & $M[\mathrm{kNm}]$ & 649.22 & & $M[\mathrm{kNm}]$ & 651.62 & \\
\hline & \multirow{2}{*}{20} & $N[\mathrm{kN}]$ & -341.8 & \multirow{2}{*}{$\begin{array}{c}\text { wind W2 } \\
\text { imp. as per Fig. 3d) }\end{array}$} & $N[\mathrm{kN}]$ & -337.2 & wind W2 \\
\hline & & $M[\mathrm{kNm}]$ & 537.11 & & $M[\mathrm{kNm}]$ & 544.59 & imp. as per Fig. 3d) \\
\hline
\end{tabular}


Table 5

The highest values of forces in mast guys - calculations taking into account the initial imperfections

\begin{tabular}{|c|c|c|c|c|c|c|}
\hline \multirow{2}{*}{ Guy level } & \multicolumn{3}{|c|}{ Imperfections $v=L / 1000$} & \multicolumn{2}{c|}{ Imperfections $v=L / 500$} \\
\cline { 2 - 7 } & \multicolumn{2}{|c|}{ Force values } & $\begin{array}{c}\text { Calculation } \\
\text { situation }\end{array}$ & \multicolumn{2}{|c|}{ Force values } & $\begin{array}{c}\text { Calculation } \\
\text { situation }\end{array}$ \\
\hline I & $S[\mathrm{kN}]$ & 200.8 & $\begin{array}{c}\text { wind W1 } \\
\text { imp. as per Fig. 3c) }\end{array}$ & $S[\mathrm{kN}]$ & 213.7 & $\begin{array}{c}\text { wind W1 } \\
\text { imp. as per Fig. 3c) }\end{array}$ \\
\hline II & $S[\mathrm{kN}]$ & 189.5 & $\begin{array}{c}\text { wind W1 } \\
\text { imp. as per Fig. } \\
\text { 3b) }\end{array}$ & $S[\mathrm{kN}]$ & 191.7 & $\begin{array}{c}\text { wind W1 } \\
\text { imp. as per Fig. 3b) }\end{array}$ \\
\hline III & $S[\mathrm{kN}]$ & 239.5 & $\begin{array}{c}\text { wind W1 } \\
\text { imp. as per Fig. } \\
\text { 3d) }\end{array}$ & $S[\mathrm{kN}]$ & 243.1 & $\begin{array}{c}\text { wind W1 } \\
\text { imp. as per Fig. 3d) }\end{array}$ \\
\hline
\end{tabular}

It is important from the structure safety point of view, to know how the noted differences in the internal force values affect the effort of particular structure elements. Checking of the mast shaft strength comes down to checking of the carrying capacity condition of a single leg member taking into account its buckling between the lattice joints. The buckling resistance of compression leg member is determined from the formula [1]:

$$
N_{b, R d}=\chi A_{1} f_{y} / \gamma_{M 1},
$$

where $A_{1}=61.2 \mathrm{~cm}^{2}-$ leg member cross-section area, $\chi=0.894-$ reduction factor calculated for the leg member buckling length $l_{1}=250 \mathrm{~cm}, \gamma_{M 1}=1.0$, therefore $N_{b, R d}=1942.3 \mathrm{kN}$.

The load capacity condition is, as per [2], as follows:

$$
N_{E d} / N_{b, R d} \leq 1,
$$

where $N_{E d}$ - leg member compression force value $\left(N_{E d}=N / 3+M / h-\right.$ in case of $\mathrm{M} \geq 0$, $N_{E d}=N / 3+M / 2 h-$ in case of $\mathrm{M}<0$ ).

Percentage utilisation of the end condition in particular spans of the analysed mast are presented in Table 6 . 
Percentage of the mast shaft spans carrying capacity condition utilisation

\begin{tabular}{|c|c|c|c|c|}
\hline \multicolumn{2}{|c|}{ Span No } & 1 & 2 & 3 \\
\hline \multirow{2}{*}{$\begin{array}{c}\text { Carrying capacity condition } \\
\text { utilization } \\
{[\%]}\end{array}$} & $\begin{array}{c}\text { Imperfections } \\
v_{0}=0\end{array}$ & 38 & 29 & 31 \\
\cline { 2 - 5 } & $\begin{array}{c}\text { Imperfections } \\
v_{0}=L / 1000\end{array}$ & 40 & 32 & 33 \\
\cline { 2 - 5 } & $\begin{array}{c}\text { Imperfections } \\
v_{0}=L / 500\end{array}$ & 43 & 33 & 34 \\
\hline
\end{tabular}

Increase of the carrying capacity utilisation in the "imperfect" structure analysis compared with a structure without initial imperfections pertains, first and foremost, to the lowest mast span and originates from a considerable increase of the span moment values at practically identical normal force values. However, it can be noted that even $30 \%$ increase of the bending moment values for the structure with $L / 500$ imperfections, compared with the "perfect" type structure, caused an increase of the carrying capacity condition "only" from 38 to $43 \%$.

The mast guys carrying capacity conditions were checked, in accordance with [9], assuming that the rope ends have been put in metal filled sleeves. Percentage utilisation of the guy carrying capacity condition at particular levels are presented in Table 7.

Table 7

Percentage of the mast guys carrying capacity condition utilisation

\begin{tabular}{|c|c|c|c|c|}
\hline \multicolumn{2}{|c|}{ Guy level } & I & II & III \\
\hline \multirow{2}{*}{$\begin{array}{c}\text { Carrying capacity condition } \\
\text { utilization } \\
{[\%]}\end{array}$} & $\begin{array}{c}\text { Imperfections } \\
v_{0}=0\end{array}$ & 34 & 34 & 43 \\
\cline { 2 - 5 } & $\begin{array}{c}\text { Imperfections } \\
v_{0}=L / 1000\end{array}$ & 37 & 35 & 44 \\
\cline { 2 - 5 } & $\begin{array}{c}\text { Imperfections } \\
v_{0}=L / 500\end{array}$ & 39 & 35 & 44 \\
\hline
\end{tabular}

All guys in the analysed structure were designed to be made of ropes featuring the same diameter, therefore, a reliable result is provided by verification calculations for the highest level guys in which the biggest tensile forces occurred. It can be noted that in the practical aspect of the verification calculations, taking into account of initial imperfections featuring even $L / 500$ value is not very significant. 


\section{REMARKS AND FINAL CONCLUSIONS}

Based on the calculations performed for a specific mast structure a quite significant impact of mast shaft imperfections in form of initial span curvature on the increase, first and foremost, of span moment values in the shaft was demonstrated. Therefore, from the point of view of structure calculation correctness as per the second order theory, the structure burdened with initial imperfections should be analysed. Unfortunately, there are no guidelines in the Eurocode [1] regarding the form of initial imperfections and their values. The value of $v_{0}=L / 1000$ assumed in this study is equal to the permissible standard assembly deviations whilst $v_{0}=L / 500$ is equal to the initial imperfections of uniform built-up columns, in accordance with [2]. However, consideration of a mast shaft as a typical uniform built-up column is arguable. Imperfections of columns of typical structures have values close to the real deflections at the structure operational stage whereas in masts the structure can sustain, due to wind load, deflections of even several meters (depending, of course, on the mast height and rigidity). Compared with such deflections, imperfections of several centimetres are small (they manifest a different order of magnitude). Assumption of the shaft imperfection as for a uniform built-up bar is, in accordance with [2], also a simplification. Imperfections in form of span buckling with maximum amplitude of $v_{0}=L / 500$ pertain to a column with hinged ends as this corresponds to its buckling form. In the case of another fixing arrangement those values will be different, e.g. for a cantilever $v_{0}=2 L / 500=L / 250$. The guy to mast shaft fixing points should be considered as elastic supports. So, the start point here should be, in the first instance, definition of proper mast buckling form and then, possible discussion on adoption of initial imperfections corresponding to this buckling form.

Calculations of the ,imperfect” type mast structures are very laborious and complicated. Therefore, from the practical point of view of mast designers, a reply to the question in which cases may initial imperfections be omitted from calculations, is significant. Also proper provision regulating these issues should be put in standard regulations. As values of the mast shaft geometrical imperfections are strictly associated with the permissible assembly deviations, it seems that when the manufacturing discipline is strict and quality control is proper, masts can be calculated disregarding the initial imperfections. The conclusions and final remarks are based on the calculations of the mast only in the framework of the standards regulations. The calculations should be confronted with the more advances masts calculations methods in the next stage, which will be performed in the near future by the author. 


\section{REFERENCES}

1. EN 1993-3-1. Eurocode 3: Design of steel structures. Part 3-1: Towers, masts and chimneys - Tower and masts.

2. EN 1993-1-1. Eurocode 3: Design of steel structures. Part 1-1: General rules and rules for buildings.

3. DIN V 4131. Antennentragwerke aus Stahl, 2008.

4. EN 1991-1-4. Eurocode 1: Actions on structures. Part 1-4: general actions - wind actions.

5. Sz. Pałkowski, On numerical analysis of masts using theory of the second order, Inżynieria i Budownictwo, 8, 436-438 [in Polish].

6. Sz. Pałkowski, Steel structures, Some issues of calculating and designing, PWN, 2009 [in Polish].

7. M. Matuszkiewicz, Computation of guyed lattice masts according to PN-EN 1993-3-1, Inżynieria i Budownictwo, 4, 194-199, 2010 [in Polish].

8. M. Matuszkiewicz, Calculation of guyed masts in accordance with EN 1993-3-1 standard taking into account mast shaft geometrical imperfections, Engineering Structures, 33, 2044-2048, 2011.

9. EN 1993-1-11. Eurocode 3: Design of steel structures. Part 1-11: Design of structures with tension components. 